\title{
HUBUNGAN KARAKTERISTIK DAN PENGETAHUAN IBU DENGAN KEMANDIRIAN TOILET TRAINING ANAK TODDLER
}

\author{
Mismadonaria, Tuti Asrianti Utami*, Anna Rejeki Simbolon \\ Program Sarjana Keperawatan, STIK Sint Carolus, Jakarta \\ "Korespondensi Penulis: tutichaidir18@gmail.com
}

\begin{abstract}
ABSTRAK
Latar Belakang : Toilet training merupakan bagian terpenting untuk perkembangan anak usia toddler (1-3 tahun), dalam proses berkemih dan defekasi. Toilet training dapat terlaksana dengan baik, tentunya membutuhkan peran serta orang tua khususnya ibu. Pengetahuan ibu diperlukan untuk memandirikan anaknya melakukan toilet training yang benar. Penelitian ini bertujuan untuk diketahuinya hubungan karakteristik dan pengetahuan responden dengan kemandirian toilet training anak toddler di Wilayah Tanah Tinggi, Jakarta.

Metode: Penelitian kuantitatif ini dengan desain deskriptif korelatif yang pendekatannya secara cross sectional. Total sampling digunakan dalam pengambilan sampel sejumlah 86 responden. Alat analisis menggunakan u ji chi square (AAP, 2020).

Hasil: Hasil penelitian didapatkan responden terbanyak memiliki pengetahuan yang baik dan perilaku yang baik dalam kemandirian toilet training anak toddler (41,8\%), usia responden yaitu 26-35 tahun sebanyak 32 (48,5\%), tingkat pendidikan responden sebagian besar berpendidikan menengah sebanyak 25 responden $(29,1 \%)$, pekerjaan responden yaitu sebagai ibu rumah tangga sebanyak 44 responden (54,3\%). Adapun hasil yang didapatkan tidak adanya hubungan antara usia $(0,091>0,05)$, pendidikan $(0,458>0,05)$ pekerjaan $(0,333>0,05)$ dan pengetahuan $(0,083>0,05)$ responden dengan kemandirian toilet training anak usia toddler.

Kesimpulan: Bedasarkan hasil penelitian, disarankan petugas kesehatan dan kader sebaiknya memberikan promosi kesehatan tentang pentingnya memandirkan toilet training yang benar dengan memperhatikan kesiapan pada anak toddler
\end{abstract}

Kata Kunci : pengetahuan, kemandirian toilet training, anak toddler

\section{THE RELATIONSHIP OF CHARACTERISTICS AND MOTHER KNOWLEDGE WITH INDEPENDENCE OF CHILDREN TODDLER TOILET TRAINING}

\begin{abstract}
Background: Toilet training is the most important part of the development of toddlers (1-3 years), in the process of urinating and defecating. Toilet training can be carried out well, of course, it requires the participation of parents, especially mothers. Mother's knowledge is needed to enable her child to do proper toilet training. This study aims to determine the relationship between characteristics and knowledge of respondents with the independence of toilet training for toddlers in Tanah Tinggi, Jakarta.

Method: This quantitative research with a correlative descriptive design with a cross-sectional approach. Total sampling used in sampling many 86 respondents. The analysis tool uses uji chi-square (AAP, 2020).

Results: The results showed that most respondents had good knowledge and good behaviour in the independence of toddler toilet training (41.8\%), the age of respondents was 26-35 years as many as 32 (48.5\%), the education level of the respondents was mostly educated Medium as many as 25 respondents (29.1\%), the respondent's occupation is as a housewife as many as 44 respondents (54.3\%). The results obtained were there was no relationship between age $(0.091>0.05)$, education $(0.458>0.05)$, work $(0.333>0.05)$ and knowledge $(0.083>0.05)$ of respondents with toddler toilet training independence.

Conclusion: Based on the results of the study, it is recommended that health workers and cadres should provide health promotion about the importance of bathing the right toilet training by paying attention to the readiness of toddlers
\end{abstract}

Keywords: knowledge, independent toilet training, toddlers 


\section{PENDAHULUAN}

Anak yang berusia 1-3 tahun disebut anak toddler, diusia ini anak sudah mampu mengeksplorasikan lingkungannya dan mencoba segala sesuatu untuk belajar mengetahui tentang dunianya khususnya yang berhubungan dengan relationship. ${ }^{1}$ Pertumbuhan dan perkembangan pada anak toddler dirasakan sangat cepat dan juga merupakan masa kritis untuk membentuk dan mempengaruhi kemandirian anak toddler, seperti halnya mengenai toilet training. ${ }^{2}$

Toilet trainning adalah pengontrolan otototot anal juga sphinter uretra ketika anak dapat mulai berjalan diantara usia 18-24 bulan. Faktor psychophysiologics salah satu perilaku yang diperlukan untuk kesiapan anak mengerjakan toilet training. ${ }^{1}$ Anak toddler ketika masa toilet training nya tidak terlewati dengan baik, akan mengalami ngompol. ${ }^{3,4}$

Di Amerika Serikat pada usia 24 bulan ada sebanyak $26 \%$ balita mengalami permasalahan dalam mengompol, pada usia 30 bulan ada sebanyak $88 \%$ dan $98 \%$ pada usia 36 bulan. ${ }^{3}$ Singapura melaporkan ada $15 \%$ anak yang usianya 5 tahun masih tetap mengompol. Sementara di Ingrgris ada 1,3\% anak laki dan 0,3\% $\%$ anak perempuan yang mempunyai kebiasaan untuk Buang Air Besar dan Buang Air Kecil di sembarang tempat sampai pada usia 7 tahun.

Profil Kesehatan Indonesia, tahun 2017 menunjukkan bahwa jumlah balita tahun 2016 ada $30 \%$ dari 258.704 .986 penduduk Indonesia Diantaranya ada 75 juta usia anak sampai prasekolah yang mengalami kesulitan mengontrol $\mathrm{BAB}$ dan BAK, hal ini terjadi karena sejak dini tidak dilatih konsep toilet training secara mandiri. ${ }^{5}$ Indonesia sekitar 50\% (52.226) kasus anak mengompol berdasarkan riwayat keluarga. Anak mempunyai risiko sebesar 44\%, jika kedua orangtuanya menderita enuresis, resiko meningkat menjadi $77 \%$ pada anaknya. ${ }^{6}$

Pengetahuan mengenai toilet training adalah hal yang penting untuk diketahui oleh seorang ibu terutama dalam menciptakan perilaku yang baik bagi anak usia toddler. Hal ini berpengaruh pada saat ibu menerapkan toilet training untuk anaknya. ${ }^{7}$ Ibu dengan berpendidikan baik berarti mempunyai pengetahuan dan sikapnya baik dalam menerapkan kemandirian toilet training. Ibu berharap anaknya akan mempunyai kemandirian dalam melakukan toilet training. $^{8}$

Kemandirian toilet training pada anak dapat terjadi sesuai dengan kesiapan diri anak juga keluarganya. Anak toddler akan siap lakukan toilet training jika secara motorik kasar sudah siap, yang mana anak dapat kuat duduk tegak sendiri dan berdiri, agar anak dapat diajarkan buang air. Anak sudah memiliki kemampuan psikologi, memerlukan suasana nyaman untuk mampu mengontrol dan konsentrasi untuk merangsang buang air besar (BAB) dan buang air kecil (BAK). 1,3

Peneliti melakukan observasi tepatnya di wilayah Tanah Tinggi, Jakarta Pusat dimana terdapat beberapa anak yang $\mathrm{BAB}$ dan $\mathrm{BAK}$ tidak sesuai tempatnya, dan sebagian ibu menerapkan kepada anaknya untuk menggunakan popok sekali pakai atau dikenal dengan pampers, padahal setiap rumah warga memiliki fasilitas toilet. Ibu mempunyai peranan penting untuk melatih kemandirian toilet training karena memiliki banyak waktu dengan anaknya di rumah. Ibu penting mengetahui lebih banyak tentang tumbuh kembang anaknya terlebih dalam hal toilet training

Penelitian ini dilakukan untuk diketahuinya hubungan karakteristik dan pengetahuan responden dengan kemandirian toilet training pada anak toddler di Wilayah Tanah Tinggi, Jakarta. Manfaat hasil penelitian ini adalah untuk memberikan informasi melalui promosi kesehatan bagi orang tua agar mempunyai pengetahuan toilet training untuk anak toddler (1-3 tahun) dan upaya-upaya yang perlu dilakukan agar mendukung keberhasilan toilet training untuk anak toddler. Penelitian lainpun dapat mengembangkan penelitian dengan menambahkan sikap dan perilaku ibu. Maka untuk itu peneliti menetapkan masalah yaitu adakah hubungan karakteristik dan pengetahuan responden terhadap kemandirian toilet training untuk anak toddler di Tanah Tinggi Jakarta?

\section{METODE PENELITIAN}

Penelitian kuantitatif ini, cross sectional desain deskriptif korelasi. Total sampling penelitian sebanyak $86 \mathrm{ibu}$, dengan kriteria ibu yang mempunyai anak toddler (1-3 tahun), ibu mengasuhnya sendiri dan tinggal di kelurahan Tanah Tinggi Jakarta, penelitian ini dilaksanakan pada Mei-Juli 2018, di Puskesmas kelurahan Tanah Tinggi Jakarta Pusat.

Kuisioner yang digunakan dalam penelitian menggunakan lembar ceklist, dengan dua kuisioner yaitu tentang pengetahuan sebanyak 14 pernyataan, dengan skala Guttman jawabannya benar atau salah. Kriteria hasil ukur terbagi atas pengetahuan kurang jika nilai $<55 \%$, pengetahuan cukup dengan nilai $56-75 \%$ dan pengetahuan baik dengan nilai $>76 \%-100 \% .^{9} \quad$ Uji validitas pengukuran kuisioner pengetahuan toilet training dilakukan pada 30 orang dihasilkan dari $r$ product moment $\alpha=5 \%$, Hasil perhitungan uji reliabilitas 
dengan nilai Cronbach alpha 0,921. Kuisioner lainnya tentang kemandirian anak toddler untuk toilet training dengan 12 pernyataan, menggunakan skala likert pernyataan sangat sering (SS), Sering (S), Jarang (J) dan Tidak pernah (TP). Hasil ukur menggunakan median terbagi atas $\geq$ median artinya mempunyai kemandirian yang baik dan $<$ median artinya mempunyai kemandirian yang buruk.

Uji validitas pengukuran kuisioner pengetahuan dan kemandirian toilet training dilakukan pada 30 orang dihasilkan $r$ product moment $\alpha=5 \%$. Hasil perhitungan uji reliabilitas kuisioner pengetahuan dengan nilai Cronbach alpha 0,921 dan kuisioner kemandirian toilet training dengan nilai Cronbach alpha 0,911 . Analisa data yang dilakukan adalah analisa univariate untuk mendapatkan data distribusi frekuensi, analisis bivariate dengan uji Chisquare. $^{10}$ Jika melihat hubungan karakteristik dan pengetahuan dengan kemandirian toilet training anak toddler. Uji etik penelitian dilakukan melalui komite etik dan sudah disetujui sesuai kaidah etik dari Komisi Etik Penelitian dan Pengembangan Kesehatan Sekolah Tinggi Ilmu Kesehatan Sint Carolus (KEPPK STIK SC).

\section{HASIL DAN PEMBAHASAN}

Tabel 1 menjelaskan dari 86 responden yang mempunyai anak toddler (1-3 tahun) responden terbanyak adalah usia dewasa akhir (3645 tahun) sebanyak $66 \quad(76,7 \%)$ responden, pekerjaan ibu rumah tangga sebanyak $81(94,2 \%)$ responden, pendidikan akhir ibu SMA-Diploma sebanyak $43(50,0 \%)$ responden, pengetahuan baik (nilainya $>76 \%-100 \%$ ) sebanyak $65 \quad(75,6 \%)$ responden, anak dengan kemandirian baik sebanyak $65(75,6 \%)$ responden.

Tabel 1. Distribusi karakteristik usia, pekerjaan, pendidikan responden dengan kemandirian toilet training anak toddler

\begin{tabular}{llcc}
\hline & Karakteristik & n & $\mathbf{\%}$ \\
\hline \multirow{2}{*}{ Usia } & $\begin{array}{l}\text { Remaja akhir }(17- \\
\text { 25 tahun) }\end{array}$ & 20 & 23,3 \\
& $\begin{array}{l}\text { Dewasa akhir }(36- \\
\text { 45 tahun) }\end{array}$ & $\mathbf{6}$ & $\mathbf{7 6 , 7}$ \\
\hline \multirow{2}{*}{ Pekerjaan } & Ibu Rumah Tangga & $\mathbf{8 1}$ & $\mathbf{9 4 , 2}$ \\
\cline { 2 - 4 } Pendidikan & Karyawan Swasta & 5 & 5,8 \\
\hline \multirow{2}{*}{ Pengetahuan } & Rendah (SD-SMP) & 35 & 40,7 \\
\hline \multirow{2}{*}{ Kemandirian } & Tinggi (SMA- & $\mathbf{5 1}$ & $\mathbf{5 9 , 3}$ \\
& Diploma) & & \\
\cline { 2 - 4 } & Baik & $\mathbf{6 7}$ & $\mathbf{7 7 , 9}$ \\
\hline & Baik $(>37)$ & $\mathbf{6 5}$ & 22,1 \\
\hline
\end{tabular}

Tabel 2 menjelaskan dari 86 responden sebanyak 34 responden $(39,5 \%)$ berusia dewasa akhir (36- 45 tahun) memiliki kemandirian toilet training anak toddler yang buruk. Hasil uji chi square $p$ value $=0,091(>0,05)$ artinya tidak ada hubungan bermakna antara usia ibu dengan kemandirian toilet training anak toddler. Penelitian ini terdapat ibu rumah tangga sebanyak $44(51,2 \%)$ responden memiliki kemandirian toilet training toddler yang baik. Hasil uji chi square dihasilkan $p$ value $=0,333(>0,05)$ artinya tidak adanya hubungan bermakna antara pekerjaan dengan kemandirian toilet training anak toddler.

Tabel 2 menunjukkan bahwa ibu dengan pendidikan tinggi sebanyak $32(37,2 \%)$ memiliki kemandirian toilet training anak toddler yang baik. Hasil uji chi square dihasilkan $p$ value = $0,458(>0,05)$ artinya tidak adanya hubungan bermakna antara pendidikan dengan kemandirian toilet training anak toddler. Tabel 2 menunjukkan bahwa ibu dengan pendidikan tinggi sebanyak 32 $(37,2 \%)$ memiliki kemandirian toilet training anak toddler yang baik. Hasil uji chi square dihasilkan $p$ value $=0,458(>0,05)$ artinya tidak adanya hubungan bermakna antara pendidikan dengan kemandirian toilet training anak todler. Tabel 2 menjelaskan ibu memiliki pengetahuan baik sebanyak 39 (58,2\%) memiliki kemandirian toilet training anak toddler yang baik. Hasil uji chi square dihasilkan $p$ value $=0,083(>0,05)$ artinya tidak adanya hubungan bermakna antara pengetahuan dengan kemandirian toilet training anak todler di Wilayah Tanah Tinggi, Jakarta.

Tabel 2. Hubungan usia, pekerjaan, pendidkan dan pengetahuan dengan kemandirian toilet training anak toddler, di wilayah Tanah Tinggi Jakarta $(\mathbf{n}=86)$

\begin{tabular}{|c|c|c|c|c|c|c|c|}
\hline \multirow{3}{*}{ Variabel } & \multirow{3}{*}{$\begin{array}{c}\text { Klasifi } \\
\text { kasi }\end{array}$} & \multicolumn{4}{|c|}{$\begin{array}{c}\text { Kemandirian } \\
\text { Toilet Training }\end{array}$} & \multirow{3}{*}{$\frac{\text { Total }}{\mathbf{N}}$} & \multirow{3}{*}{$\begin{array}{l}\text { P value } \\
\% \\
\end{array}$} \\
\hline & & \multicolumn{2}{|c|}{ Baik } & \multicolumn{2}{|c|}{ Buruk } & & \\
\hline & & $\mathrm{n}$ & $\%$ & $\mathrm{n}$ & $\%$ & & \\
\hline \multirow{2}{*}{ Usia } & $\begin{array}{l}\text { Remaja } \\
\text { akhir }\end{array}$ & 14 & 16,3 & 6 & 7,0 & 20 & \multirow{2}{*}{0,091} \\
\hline & $\begin{array}{l}\text { Dewasa } \\
\text { Akhir } \\
\end{array}$ & 32 & 37,2 & 34 & 39,5 & 66 & \\
\hline \multirow{2}{*}{ Pekerjaan } & IRT & 44 & 51,2 & 37 & 43,0 & 81 & \multirow[b]{2}{*}{$-0,333$} \\
\hline & $\begin{array}{l}\begin{array}{l}\text { Wiraswa } \\
\text { sta }\end{array} \\
\end{array}$ & 1 & 1,2 & 4 & 4,6 & 5 & \\
\hline \multirow{2}{*}{ Pendidikan } & Rendah & 15 & 17,4 & 20 & 23,3 & 35 & \multirow{2}{*}{ - 0,458} \\
\hline & Tinggi & 32 & 37,2 & 19 & 22,1 & 51 & \\
\hline \multirow{2}{*}{ Pengetahuan } & Baik & 39 & 58,2 & 28 & 41,8 & 67 & \multirow{2}{*}{ - 0,083} \\
\hline & Cukup & 7 & 36,8 & 12 & 63,2 & 19 & \\
\hline
\end{tabular}

Kemandirian toilet training anak toddler terbentuk karena dukungan keluarga terutama 
orang tua yang membiasakan toilet training untuk keseharian. Melatih toilet training menjadi salah satu adanya kemandirian yang terjadi pada anak, sebab anak usia toddler mampu untuk mengerjakan BAK dan BAB sendiri.

Hasil penelitian yang menyimpulkan bahwa dari 94 responden terdiri dari usia dewasa muda (21-39 tahun) sebanyak $82 \quad(87,2 \%)$ responden lebih mudah memahami mengenai praktik toilet training pada anak toddler dan memiliki pengetahuan yang lebih baik dan mudah menerimaan informasi. Semakin umurnya bertambah maka semakin berkembang daya tangkap dan kemampuan berpikir seseorang dan akan membuat pengetahuan semakin baik pada seseorang. ${ }^{10}$

Berbeda dengan penelitian ini sebanyak 34 (39,5\%) responden berusia dewasa akhir (36- 45 tahun) memiliki kemandirian toilet training anak toddler yang buruk, ternyata semakin cukup usia ibu, belum tentu ibu memiliki tingkat kematangan dan kedewasaan dalam memandirikan toilet training anaknya. Terkadang ibu-ibu ini masih memiliki rasa ketergantungan yang lebih terhadap orang tuanya dan masih dominan mempercayakan orang tuanya dalam mengurus dan merawat anaknya, termasuk memandirikan dalam hal toilet training.

Toilet training berproses karena terjadinya perubahan impuls atau rangsangan juga pola pikir anak dalam mengerjakan proses BAK dan BAB. ${ }^{12}$ Ketika ibu mampu mengenali tingkat kesiapan anak seperti anak mampu mengontrol volunter sfinger anal juga uretral mulai usia 18-24 bulan, selama 2 jam tidak mengompol, popok basah jumlahnya sudah mulai sedikit, ketika anak tidur pada siang hari sudah tidak mengompol lagi dan defekasi teratur, anak sudah bisa duduk, berjalan dan berjongkok dan sudah mampu membuka pakaian sendiri, secara psikologis anak juga mampu mengekspresikan keinginannya untuk BAK atau BAB. ${ }^{1}$ Meningkatkan kemandirian toilet training anak toddler sangat diperlukan kemampuan orangtua mengenali tingkat kesiapan anak, orangtua punya keinginan untuk meluangkan waktu dan melatih anaknya, stress tidak terjadi ataupun perubahan keadaan keluarga misalnya perceraian, berpindah rumah atau terjadi sibling. ${ }^{1}$

Anak-anak diharapkan dapat mengontrol buang air kecil secara mandiri. Ibu dalam mengajar praktik menggunakan toilet, sebaiknya dengan metode yang tepat, benar dan mudah dipahami anak. Sehingga anak-anak akan dilatih pergi ke toilet tanpa harus menggunakan popok atau pampers lagi. ${ }^{13}$

Pendidikan diperlukan seseorang untuk mendapatkan suatu informasi. ${ }^{8}$ Pendidikan seseorang yang semakin tinggi maka tingkat pemahaman akan meningkat sehingga tepat dalam menentukan sikap. Pendidikan ibu mempengaruhi kesiapan toilet training, ibu dengan pendidikan tinggi mempunyai pengetahuan luas dan memilih gaya hidup modern seperti penggunaan diapers pada anaknya, sehingga hal tersebut memperhambat kesiapan toilet training. ${ }^{14}$

Tahun 2015 penelitian ini menjelaskan adanya hubungan yang bermakna antara pendidikan ibu dengan toilet training dan faktor yang mempengaruhi dengan $\mathrm{p}=0,03(p<0,05)$, sampel sebanyak 1500 responden. Penelitian ini menghasilkan terdapatnya perbedaan antara responden yang pendidikannya lebih dari 12 tahun, akan memiliki tingkat pelatihan toileting lebih baik dibandingkan dengan responden yang pendidikan nya kurang dari 12 tahun, sehingga pendidikan ibu sangat mempengaruhi keberhasilan toilet training pada anaknya. ${ }^{2}$

Penelitian ini menyimpulkan tidak adanya hubungan yang bermakna antara pendidikan dan tingkat pengetahuan dengan sikap ibu untuk toilet training $\mathrm{p}=0,857$ ( $p$ value $<0,05)$, sampel sebanyak 51 responden, dengan tingkat pindidikan akhir SMA sebanyak 29 responden (70,8\%). Salah satu faktor penyebab rendah nya tingkat pendidikan yaitu karena masalah ekonominya, juga kemauan yang kurang dalam mendapatkan pendidikan tinggi. ${ }^{14}$

Pekerjaan adalah suatu tindakan seseorang dalam melakukan suatu kegiatan yang mencukupi kebutuhan hidupnya bersama keluarga. Pekerjaan tidak sebagai sumber kesenangan, tetapi bagi sebagian orang yang melakukannya secara terpaksa akan menimbulkan kebosanan serta akan mengalami berbagai tantangan. Bekerja sering kali dilakukan oleh ibu-ibu, hal tersebut akan mempunyai pengaruh bagi kehidupan keluarganya. $^{8}$

Penelitian ini menyimpulkan bahwa sebanyak 44 responden $(51,2 \%)$ bekerja sebagai ibu rumah tangga dan memiliki perilaku yang buruk sebanyak 37 responden $(43,0 \%)$. Hasil bivariat dengan chi square didapatkan nilai pvalue sebesar 0,333 ( $p$ value $<0,05)$ berarti tidak adanya hubungan bermakna antara pekerjaan dengan perilaku ibu dalam kemandirian toilet training di Wilayah Tanah Tinggi, Jakarta Pusat.

Penelitian ini menyimpulkan tidak adanya hubungan antara pekerjaan ibu dengan toilet training dan faktor yang mempengaruhi $\mathrm{p}=0,635$. $(p$ value $<0,05)$, sampel sebanyak 1500 responden. ${ }^{2}$ Kesimpulan dalam penelitian ini tidak adanya perbedaan antara responden yang bekerja dengan responden yang tidak bekerja dalam melakukan toilet training. Hal yang sama disampaikan pada penelitian ini yang menyimpulkan tidak terdapatnya hubungan antara 
pekerjaan ibu dengan keberhasilan toilet training pada anak toddler. ${ }^{15}$ Ibu bekerja dapat melakukan toilet training pada anaknya, waktu yang lebih banyak akan dimiliki oleh ibu yang tidak bekerja sehingga dapat mencari informasi menggunakan media seperti TV dan kegiatan posyandu dan PKK. Ibu-ibu ketika berkumpul dapat saling bertukar informasi dan pengalaman.

Hasil penelitian ini menyimpulkan bahwa adanya hubungan antara pekerjaan dan peran sebagai ibu terhadap keberhasilan toilet training anaknya dengan nilai $\mathrm{p}=0,004(p<0,05)$, sebanyak $80 \%$ responden tidak bekerja, maka dapat disimpulkan pekerjaan akan mempengaruhi peran yang dimiliki orang tua terhadap keberhasilan toilet training, karena waktu yang diberikan kepada anak tidak maksimal. Ketika harus melatih dan membimbing toilet training untuk anak toddler nya. ${ }^{16}$

Pengetahuan sebagai hasil pengindraan seseorang atau hasil tahu setelah orang tersebut mengadakan pengindraan pada suatu objek tertentu dan merupakan domain yang penting untuk membentukan tindakan seseorang. ${ }^{8} \quad$ Tabel 2 menjelaskan bahwa sebagian besar pengetahuan ibu mempunyai pengetahuan baik dengan kemandirian toilet training anak usia toddler baik sebanyak $39(58,2 \%)$ responden dan pengetahuan cukup sebanyak $7(36,8 \%)$ responden. Ibu yang mempunyai pengetahuan baik dan perilaku buruk berjumlah $28(32,6 \%)$ responden dan ibu dengan pengetahuan cukup dan memiliki perilaku yang buruk sebanyak 12 (14\%) responden.

Kuisioner pernyataan pengetahuan terbagi atas 3 kategori yang sesuai dengan tingkat pengetahuan yaitu kategori pertama adalah tahu, yang membahas mengenai definisi toilet training. Yang menjawab benar sebanyak 83 responden (96,5\%), hal ini menunjukkan bahwa responden mengetahui salah satu tanda bahwa anak telah siap dapat diajarkan toilet training yaitu anak sudah mampu bicara, duduk dan berjalan. Kategori kedua yaitu memahami, yang membahas mengenai pemahaman responden tentang pelaksanaan dan teknik toilet training, yang menjawab dengan benar sebanyak 81 responden $(94,2 \%)$. Cara melatih anak dalam toilet training yaitu dengan memberikan waktu anak untuk memperhatikan ibu ketika mengajaknya ke kamar mandi sehingga membuat anak toddler tertarik untuk melakukan toilet training. Kategori ketiga yaitu aplikasi, yang membahas mengenai faktor-faktor, yang menjawab benar sebanyak 64 responden $(74,4 \%)$. Hal ini menjelaskan jika sebagian banyak responden mengetahui hal-hal yang membuat anak mengalami keterlambatan berpartisipasi dengan lingkungan dan akan membuat anak menjadi tidak percaya diri yaitu penggunaan Diapers.
Penggunaan diapers akan menunda keinginan anak toddler untuk mandiri untuk melakukan toilet training. Anak menjadi malas untuk berjalan dan duduk di toilet melaksanakan toilet training. ${ }^{6}$

Penelitian ini menyimpulkan adanya hubungan bermakna antara pengetahuan ibu dalam mengaplikasikan kesiapan toilet training anak usia 2-4 tahun, dengan nilai $\mathrm{p}=0,030$ ( $p$ value $<0,05)$. Bedasarkan hasil penelitian disimpulkan bahwa sebanyak 13 responden $(69,2 \%)$ memiliki pengetahuan yang baik dan sebanyak 9 responden $(64,3 \%)$ berpendidikan kurang sedangkan 16 responden $(76,2 \%)$ tidak memiliki kesiapan dalam toilet training. ${ }^{17}$

Penelitian ini menyimpulkan tidak adanya hubungan bermakna antara pengetahuan ibu dengan kebiasaan mengompol anak prasekolah dengan nilai $\mathrm{p}=0,232$ ( $p$ value $>0,05)$ sebanyak 82 responden. Bedasarkan hasil penelitian disimpulkan pengetahuan yang baik tidak semuanya memiliki sikap baik pada saat menerapkan toilet training anak toddler. ${ }^{5}$ Penelitian ini menyimpulkan ibu dengan pengetahuan baik, karena mempunyai pengalaman mengasuh anak yang sebelumnya dan memiliki tingkat pendidikan menengah. Ibu dengan pendidikan yang tinggi dapat membuat individu berkembang dan lebih mudah memahami sesuatu. Pada penelitian ini didapatkan sebagian besar ibu berpendidikan menengah (SMA), memiliki wawasan yang cukup luas dibandingkan ibu berpendidikan akhir lebih rendah dengan pengetahuan responden yang masih kurang. ${ }^{18}$ Karena ibu dengan anaknya yang toddler tidak pernah terpapar informasi mengenai toilet training. Setidaknya ibu mampu menilai kesiapan anak sebelum proses tersebut, misalnya anak menunjukkan keinginan dan kebutuhan secara verbal dan memiliki ketrampilan untuk duduk di kursi toilet. ${ }^{19,20}$

Menurut peneliti, pengetahuan ibu sangat berpengaruh dalam pelaksanaan kemandirian toilet training anaknya, dimana ibu yang mempunyai pengetahuan baik selalu mencari tahu hal-hal atau informasi yang baik tentang cara-cara mendidik anak-anaknya yang toddler terutama dalam hal toilet training. Pentingnya diselenggarakan pendidikan dan promosi kesehatan karena dapat meningkatkan pengetahuan dan mengubah perilaku dengan melatih dan melaksanakan kemandirian anak toddler dalam toilet training ${ }^{8}$ dan promosi kesehatan selain dapat meningkatkan pengetahuan, seseorang dapat dapat menjadi lebih patuh $^{21}$ 


\section{KESIMPULAN}

Berdasarkan penelitian yang dilakukan di wilayah Tanah Tinggi, Jakarta tidak adanya hubungan bermakna antara pengetahuan dengan perilaku ibu untuk kemandirian toilet training anak toddler $(\mathrm{p}=0,083)$. Toilet training pada umumnya dilakukan oleh semua anak ketika dimulai fase kemandirian, anak akan mulai mengerti dan mengontrol BAK dan BAB. Kesiapan inilah yang akan memampukan anak mempunyai kemandirian dalam mengontrol BAK dan BAB.

Ketrampilan anak untuk toilet training diperlukan latihan dan kesiapan, sehingga sebaiknya orangtua tidak lagi menunda sikecil untuk diajarkan toilet training. Ketika usia anak antara 12-36 bulan harapannya orangtua dapat memulai untuk mengajarkan dan melatih toilet training anaknya.

Perlunya diberikan promosi kesehatan mengenai toilet training kepada seluruh orang tua dengan anak toddler dalam mengajarkan dan menerapkan anak untuk melakukan toilet training, sehingga anak-anak mampu mengerjakan toilet training dengan benar. Peneliti menyarankan kepada peneliti selanjutnya untuk meneliti faktorfaktor motivasi, lingkungan, peran masyarakat, sosial budaya yang dapat mempengaruhi tingkat pegetahuan ibu terhadap toilet training.

\section{UCAPAN TERIMAKASIH}

Penulis mengucapkan terimakasih kepada Puskesmas kelurahan Tanah Tinggi Jakarta Pusat, Sekolah Tinggi Ilmu Kesehatan Sint Carolus dan berbagai pihak yang telah membantu penulisan artikel ini. Terimakasih pula kepada tim reviewer Jurnal Bahana Kesehatan Masyarakat atas saran masukan untuk penyempurnaan tulisan ini.

\section{DAFTAR PUSTAKA}

1. Valerie \& K. The Perils and Pitfalls of Potty Training. 2016;45(6), e199-201.

2. Tarhan H, Çakmak Ö, Akarken İ, Ekin RG, Ün S, Uzelli $\mathrm{D}$, et al. Toilet training age and influencing factors: A multicenter study. Turk J Pediatr. 2015;57(2):172-6.

3. Andresni H, Zahtamal Z, Septiani W, Mitra M, Lita L. Efektivitas Edukasi Toilet Training terhadap Perilaku Ibu dan Kemampuan Toilet Training Anak Usia 18-36 Bulan. J Kesehat Komunitas [Internet]. 2019;5(2):49-55. Available from http://jurnal.htp.ac.id/index.php/keskom/article/view 1288

4. Kemenkes. Kondisi pencapaian program kesehatan anak indonesia. 2013.

5. Ningsih SF. Hubungan Pengetahuan Dan Perilaku Ibu Dalam Menerapkan Toilet Training Dengan Kebiasaan Mengompol [Internet]. 2012. 1 p. Available from: hubungan pengetahuan dan perilaku ibu dalam menerapkan toilet training dengan kebiasaan mengompol

6. Wijarnako, J., \& Setiawati E. Ayah baik - ibu baik parenting era digital. Jakarta; 2017

7. Marilyn J. Hockenberry DW. Wong 's Essentials of Pediatric Nursing [Internet]. St.Louis Missouri; 2013. Available from: http://evolve.elsevier.com

8. Notoatmodjo. Promosi kesehatan teori dan aplikasinya. Jakarta: PT Rineka Cipta.; 2014.

9. Polit, D. F., \& Beck CT. Study guide for essentials of nursing research: appraising evidence for nursing practice. Lippincott Williams \& Wilkins.; 2013.

10. Lestari P, Adi H, SpKom Mk, Supriyono M, Program Studi AS, Keperawatan STIKES Telogorejo Semarang I, et al. Hubungan Antara Tingkat Pengtahuan Ibu Tentang Toilet Training Dengan Praktik Ibu Dalam Penggunaan Diapers Pada Anak Usia Toddler (1-3 Tahun) Di Kelurahaa Putat Purwodadi. 2013;1-7.

11. Jamaan T. Guide to healthy child development Bogor Utara: Onbloss Creative; 2017.

12. Albaramki JH, Allawama MA, Yousef AMF. Toilet training and influencing factors that affect initiation and duration of training: A cross sectional study. Iran J Pediatr. 2017;27(3):0-4.

13. van Nunen K, Kaerts N, Wyndaele JJ, Vermandel A, van Hal G V. Parents' views on toilet training (TT): A quantitative study to identify the beliefs and attitudes of parents concerning TT. J Child Heal Care. 2015;19(2):265-74.

14. Elsera C. Tingkat Pengetahuan Berhubungan dengan Sikap Ibu dalam Toilet Training pada Toddler. J Ners dan Kebidanan Indones. 2016;4(1):35.

15. Eka Sarofah Ningsih. Hubungan Pola Asuh Orang Tua Dengan Tingkat Keberhasilan Toilet Training Pada Anak Usia 18-36 Bulan. J Kebidanan Univ Islam Lamongan. 2018;10(2):1-25.

16. Risfan, B., \& Peni T (2012). Pengaruh Peran Ibu Dengan Keberhasilan Toilet Training Pada Anak Usia Toddler Di Play Group Tarbiyatush Shibiyan Mojoanyar Mojokerto. Hospital Majapahit. . J Ilm Kesehat Politeh Kesehat Majapahit Mojokerto. 2012;4 (1).

17. Kartini MAULI. Faktor-faktor yang mempengaruhi ibu dalam mengaplikasikan kesiapan toilet training pada anak usia 2-4 tahun di Desa Miruk Kecamatan Krueng Barona Jaya Kabupaten Aceh Besar. Stikes U'Budiyah banda Aceh. 2013;

18. Triningsih T. Pengaruh Pendidikan Kesehatan Toilet Training Terhadap Tingkat Pengetahuan Ibu Tentang Toilet Training Di PAUD Tunas Harapan Kutoarjo Purworejo. J Komun Kesehat. 2014;9(5(2))

19. Sharma P, Gurung G, Regmi S. Knowledge, attitude and practice regarding toilet training among mothers of toddler at Kalika Municipality, Chitwan. J Chitwan Med Coll. 2018;8(1):36-42.

20. Li WHC, Chung JOK, Ho KY, Kwok BMC. Play interventions to reduce anxiety and negative 
emotions in hospitalized children. BMC Pediatr [Internet]. 2016;16(1):1-9. Available from: http://dx.doi.org/10.1186/s12887-016-0570-5

21. Utami TA. Promosi Kesehatan Nola Pender Berpengaruh Terhadap Pengetahuan dan Kepatuhan ODHA Minum ARV. J Ners dan Kebidanan Indones. 2017;5(1):58 